\title{
How Andre Agassi helped me during my cardiothoracic surgery training
}

\author{
Ali N. Ibrahimiye, MD
}

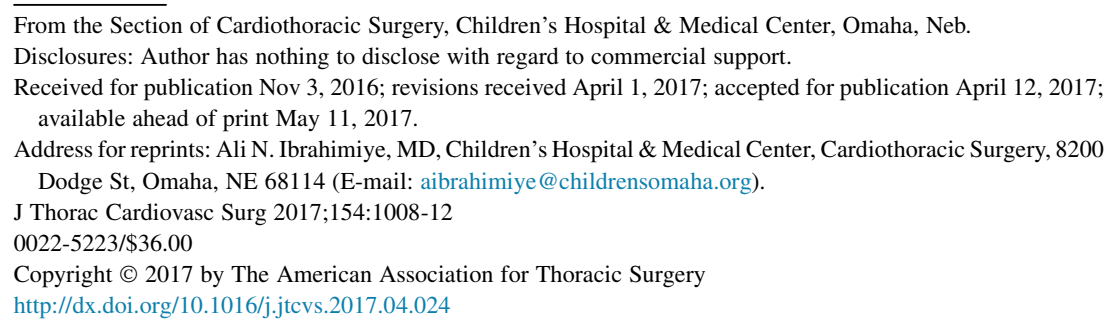

Whether they are tennis fans or not, I encourage all my colleagues, friends, and residents to read Andre Agassi's highly acclaimed autobiography, Open. ${ }^{1}$ It tells the story of the fourth child of an immigrant family from Iran and how, against the odds, he became one of the greatest tennis players of all time. Andre Agassi's parents had never played tennis in their lives. His father, Michael (Emmanuel) Agossian, maintained the clay tennis court near the American military base before the revolution and watched GIs play this really cool game in their fancy white outfits. Back then, he decided that he was going to make sure that his children learned this game and became good at it. Andre and his family lived in Las Vegas, not the flashy Strip but rather in the poor outskirts. Joining a tennis club was not an option. So, his father built an asphalt tennis court in the backyard. He purchased hundreds of used tennis balls from the local country club, and he made sure that Andre hit a thousand balls every single day, even when it was $100^{\circ} \mathrm{F}$ outside. His son asked him once, "Why one thousand?" He replied, "Because if you hit one thousand balls every day, in 3 years you will have hit one million balls, and nobody can beat a man who has hit one million balls!" ${ }^{1}$ And he was right. Andre Agassi became the first male tennis player to win all 4 Grand Slam tournaments on 3 different surfaces. He won the Olympic gold medal in Atlanta in 1996, and he led Team USA to 3 Davis Cup championships. To this day, Agassi is considered by many tennis gurus and other professional players to have the best forehand and to be the best returner of all time.

Now, back to cardiothoracic surgery. What did I learn from Andre Agassi that helped me during my training and made me a better person, doctor, and surgeon? After all, if surgery is tennis, then cardiac surgery is Wimbledon, and we all aspire to win the Cup. First, I learned that practice makes perfect, and the best way to practice is simulation. Second, I learned that I need to study my opponent. Third, I learned that I need to build a reliable team. Fourth,

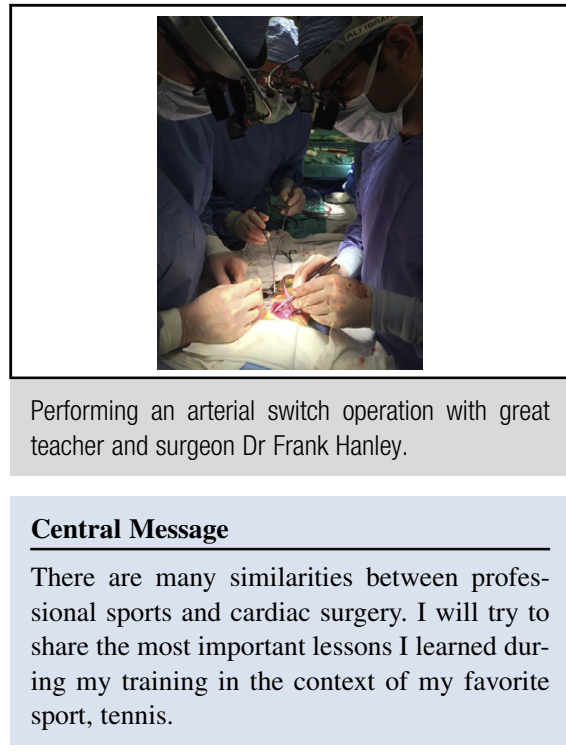

See Editorial Commentary page 1013.

learned that I need to take care of myself, so that I can stay healthy. Fifth, I learned that I need to prepare myself mentally for the game-and for all possible outcomesbefore the game. And last, but not least, I learned that I need to have a strong social support network.

\section{SIMULATION: PRACTICE MAKES PERFECT}

Andre Agassi was a skinny little kid with no access to the country club tennis courts, but he had a racquet and a lot of tennis balls. So, he hit them thousand times a day, until they invited him to the country club.

I have heard it many times, and I still hear it today: "The best way to learn how to operate is in the operating room, on patients." I disagree. There is no discipline other than surgery in which trainees learn to perform highly complex tasks in real-life situations. There is overwhelming evidence from professional sports, aviation, and the military that simulation is great way to prepare trainees for real-life situations.

Numerous randomized studies have demonstrated the transferability of surgical skills and behavior from the simulation laboratory to the clinical setting. In a recent study entitled "Simulation-Based Training in Cardiac Surgery," Feins and colleagues ${ }^{2}$ showed that overall performance in 
component tasks and complete cardiac surgical procedures improved with simulation-based training. ${ }^{3}$

It is critical, however, to emphasize the importance of deliberate, proper practice. Otherwise, trainees can develop bad habits that may be hard to break later in their careers.

I can hear some trainees say that their programs are very busy, and that they get so much operative experience that they do not need to practice on simulation models. Within the restrictions of the 80-hour work week, however, even if a trainee does 2 cases a day as the primary surgeonand this is rarely the case before the chief year-it is still not enough for mastery. Training on simulation models, such as the one that the Thoracic Surgery Directors Association distributed to the programs a few years ago, is very important to supplement and improve the clinical experience.

I spent a lot of time practicing my technique on various simulation models, either ones that I made myself or the Thoracic Surgery Directors Association coronary anastomosis and aortic root models. ${ }^{3,4}$ But one does not even need a model. A peach can be a heart, and a tissue paper can simulate a pulmonary artery.

It all boils down to the fact, that from the perspective of your upper extremity and hand muscles, it makes no difference whether you are sewing 2 noodles together or making a thoracic artery-to-left anterior descending coronary artery anastomosis. It is all about improving your muscle memory and reinforcing the neuromuscular pathways that allow you to complete a task efficiently and smoothly.

The more proficient a trainee becomes at performing a task, the more likely it is that he or she will be given opportunities in the operating room and be trusted to take on more challenging responsibilities.

\section{STUDY YOUR OPPONENT}

All professional athletes, like Andre Agassi, study their opponents. They watch videos and study their techniques and weaknesses. This helps them to develop a game plan, a strategy. The patient's pathology is the surgeon's opponent. Whether it is hypoplastic left heart syndrome or coronary artery disease, to win, the surgeon must study this opponent carefully. A deep understanding of anatomy, pathology, and physiology is a trait that all great surgeons have in common.

In our specialty, a basic fund of knowledge comes from textbooks, the medical literature, didactics during our training, and bedside and intraoperative teaching by faculty. Cardiothoracic surgery is constantly evolving, and that is what makes our specialty so much fun and so interesting. It is very important, however, to reinforce and improve your foundation by reading our national society journals and by attending meetings.

During my training, I found it very helpful to read the corresponding chapter from Sabiston's Textbook of Surgery before my assigned case and to review any relevant diagnostic imaging the day before. This practice helped me in 2 different ways. First, I became better prepared for the case. Second, I became better at interpreting angiograms and echocardiograms. I cannot emphasize enough how important it is for a cardiothoracic surgeon to become self-sufficient in reading angiograms and echocardiograms.

As one of my favorite mentors from general surgery residency, D. Paul Starker, said, it does not matter that you know how to operate, if you do not know when to operate and which operation to do.

\section{TEAM BUILDING AND COMMUNICATION}

Tennis may seem like an individual sport, but great tennis players have very strong teams, and their success is the result of a well-planned, masterfully executed team effort. Andre Agassi always had 3 people in his corner: his personal trainer, his coach, and his agent. His real team, however, which he built during years of play, was much bigger. His real team included the crowd, the ball boys and girls, reporters, and even fans watching him on television. You may have noticed that the crowd does not necessarily cheer for the better player or the clear favorite. It is also not uncommon in tennis for a player to win the match after being down by 2 sets. Did you ever wonder why? Its not as though you are from New York and you have to support the New York Nets even though they are having a terrible season. The crowd in tennis does not have any geographic or national loyalty to any player. When 20,000 fans are cheering for you, its hard for your opponent to think straight. When Agassi finished his last match at the US Open in 2006, the 23,771 fans in Arthur Ashe Stadium gave him a standing ovation, and most of them had tears in their eyes. The ability of Andre Agassi to communicate with people and to earn their support is a quality that great leaders share across disciplines, and cardiac surgery is not an exception.

There is no question, cardiothoracic surgery is a team sport. Who is on the team? The patient, the surgeon, the cardiologist, the anesthesiologist, the perfusionist, the physician assistants, the nurses, the residents. We can make the list even longer. The surgeon is the designated leader of this team, and as the leader, it is the surgeon's responsibility to make sure that all team members work in harmony with the common goal of perfect surgical outcome for the patient. This is easier said than done under stressful situations, such as cardiothoracic surgery.

We all start our careers with different sets of innate abilities. A lot of these desired leadership skills can be learned and improved, however, and residency is the ideal time to start working on these skills. I had the opportunity to participate in several leadership courses and seminars offered by either the Society of Thoracic Surgeons, the American College of Surgeons, or my own hospital. I have to admit that I was skeptical at first, but I found the lessons to be very 
valuable and applicable to my daily practice. Having said that, I believe that the best way to develop good communications skills in the operating room is to observe and learn from surgeons whom you consider to be role models. It is equally important to observe and learn from bad examples.

The following words from Major General John M. Scofield's address on August 1879 to the Corps of Cadets at West Point Academy summarize the type of leadership to which we all should aspire: "He who feels the respect which is due to others cannot fail to inspire in them regard for himself, while he who feels, and hence manifests, disrespect toward others, especially his inferiors, cannot fail to inspire hatred against himself."

\section{PHYSICAL CONDITIONING}

As the fountain of youth started to dry out, Andre Agassi noticed that he was getting tired more easily, and he no longer had the stamina to fight for more than 3 sets. Then he started suffering from back and knee injuries. He fell to number 144 in the Association of Tennis Professionals tour ranking in 1 year. What do you think he did? First, he took a break. He realized that pushing his body was making the situation worse. He took enough time off to heal his injuries. He then found a new personal trainer, who happened to be the trainer for the University of Nevada football team. One of my favorite anecdotes from the book is the following, when his trainer asks Agassi what he does for conditioning. He tells the trainer that he runs for 10 miles. Then his trainer asks him if he ever runs for 10 miles at a slow pace during a match. The answer is clearly no. He was probably hurting himself by running 10 miles under the Nevada sun. The take-home message is that working out is good; working out in a way that supplements your craft is even better.

Without a doubt, cardiac surgery is one of the most physically demanding specialties out there. Not everyone can stand on their feet for 10 hours at a time without going to the bathroom or drinking water. Surgeons are expected to be tough. They are expected to resist starvation and dehydration while performing highly complicated tasks and making life and death decisions. But does this make sense? There will be times when we all have to push ourselves, but if you constantly push your body, it will eventually crack somewhere. Even as a resident, my body cracked during a lung transplant when I had renal colic develop. Despite warnings from friends, mentors, and my doctor that I did not drink enough water, I believed that standing up for 10 hours without taking a single break made me a stronger surgeon. Well, it did not. It made me a sick surgeon. I learned a lot from this minor health problem, and it is now my practice to take a 5-minute break every 3 to 4 hours to drink water and stretch. I would encourage everyone to take a water break every 3 to 4 hours. This may seem unrealistic to trainees. During my training, when my faculty suggested a take a break, I never accepted. I incorrectly assumed that they would think less of me. This is not true. There will be times during a case, such as cooling, rewarming, or just reperfusing the heart, when it would be perfectly appropriate to take a 5-minute break to drink water. Cardiothoracic surgeons are not shy in expressing their opinions. If a faculty member offers you a break, it is because he or she thinks that it is perfectly acceptable.

Through the years, I also witnessed several senior surgeons take time off to get hip, knee, or cervical spine surgery. Some dismiss this very real threat of potentially serious health problems by saying that "it comes with the territory." I only agree with this view partially. As cardiothoracic surgeons, we are certainly more likely to suffer from musculoskeletal aches and pains, but there are things that we can do to prevent real injury. I think a big misconception is that you have to spend hours in the gym to see an effect. That is simply not true. One can complete an effective work out specifically designed to strengthen as well as stretch the back and core muscles well within $30 \mathrm{mi}-$ nutes and without even going to the gym. An exercise regimen focused on stretching, calisthenics, and certain yoga poses may be very beneficial in relieving the stress of long hours in the operating room.

Just because you are not sick does not mean that you are healthy. Do not wait until you get sick, so that you can practice this great art as long as you wish and not as long as you can.

\section{MENTAL PREPAREDNESS: THE BODY ACHIEVES WHAT THE MIND BELIEVES}

The Association of Tennis Professionals ranks the best thousand professional tennis players in the world according to a specific point system. Players can win points and increase their rankings by playing many tournaments and by qualifying for major tournaments without even winning a single match. It sounds fairly simple. The top 50 players are considered elite players who have won some tournaments. Among these, the top 10 usually consists of Grand Slam winners and the greatest players. The players in the top 50 constantly play against each other. These 50 players are technically and physically at the same level. The major difference between the champions and the rest is their mental fitness. I would like to give a specific example to illustrate the point that I am trying to make. A top-10 player, such as Agassi, is more likely to serve an ace when he or she is leading by 2 sets. A standard player is more likely to miss his or her first serve or even have a double fault while leading by 2 sets against a top player. And this phenomenon happens all the time in tennis. Why do players who are physically equal behave so differently under stress? The best performers prepare not only their bodies but also their minds for the game. 
The biggest different between average surgeons and elite surgeons is not the number of mistakes they make, but how they handle their mistakes. This is where the concept of "failure to rescue" comes into play. An effective way to avoid failure to rescue is by mentally preparing for different scenarios before the operation.

Dr Yoshifumi Naka was the first person to introduce me to the concept of mentally preparing for the case and mental imagery. Let's say that you are assigned to do an aortic root replacement the next day. Before you go to bed, you should close your eyes and imagine every step of the case, from positioning the patient until closing the skin. When I say positioning the patient, I mean it. Because how you position the patient influences how you make your incision, and that influences how you make your sternotomy. Once you get comfortable enough to go through a case, this exercise will only take a few minutes. And when you reach that comfort zone, you need to push yourself by making the exercise more challenging. For example, start adding complications and surprises to the scenario. What will you do if you get into the right ventricle? How will you handle an air embolus? What if you are unable to wean the patient from bypass? It is easier to execute a backup plan that is already in place than to come up with a backup plan in the moment. In addition, asking for help from a senior more experienced surgeon is a sign of maturity not of weakness.

I also would urge all trainees not to underestimate first assisting. First assisting can be a great mental exercise, if you choose to participate actively rather than to follow commands. During my congenital cardiac surgery fellowship, I had the great privilege to work with Dr Frank Hanley. Every Wednesday, we would do a unifocalization. For those not familiar with the term, unifocalization is a procedure developed by Dr Hanley to rehabilitate pulmonary arteries in patients with tetralogy of Fallot, pulmonary atresia, and major aortopulmonary collaterals. The surgery typically lasts 10 to 12 hours with 8 to 10 hours on bypass, during which time we reconstruct pulmonary arteries with homograft material and 8.0 polypropylene suture. I would not be exaggerating at all if I said that I followed Dr Hanley at least for 1000 hours during my 2 years of training with him, and I learned so much from the experience. I started playing a game in my mind in which I forced myself to predict his next move or where the needle would go in the tissue next.

Last, but not least, an important component of mental strength has to do with how a surgeon deals with loss or suboptimal outcome. Despite our best efforts, we will each have to face the loss of our patients. That is part of our specialty. In a specialty in which the rewards are so great, the losses are proportionately painful. It takes a lot of mental strength to get over a loss and come back the next day and give $100 \%$ for the next patient. I am not sure that there is a way to prepare for this. The only thing that has helped me get over the loss of my patients is knowing that I have done everything I can.

In summary, take a few minutes before lights out. Process your day, put any worries or lessons on paper, and prepare mentally for tomorrow.

\section{SOCIAL SUPPORT NETWORK}

"Why do we fall?" asks Alfred of a young Bruce Wayne, and he replies, "So we can learn how to pick ourselves up." Cardiothoracic surgery training is no walk in the park. There will be good days and bad days. There will be times that you doubt your skills and potential. There will be times that you question your career choices. A survey done among members of the American College of Surgeons revealed that $40 \%$ of surgeons met criteria for burnout, defined as a high emotional exhaustion score or a high depersonalization score. The most commonly reported factor contributing to burnout was difficulty with work-life balance. .,6 $^{-1}$

When you fall, and you will fall, who will help you get up? I cannot imagine going through training without the support of my family and my fellow residents. I would encourage all trainees to invest in their social support networks. For me, it was my wife and 2 children. Their presence has always been a constant reminder of what is really important in life. I have had some colleagues who dragged their feet when it was time to go home. They would find excuses to stay in the hospital and create work for themselves. And they kept feeding themselves the same lie, that the patients needed them and so they had to stay in the hospital. Believe me when I tell you that the hospital, the department, and the patients will be just fine without you. Nowadays, with the work-hour regulations and night float, the system is set such that the patient care will not be compromised when you go home. I learned that an efficient and productive way to balance work and home life is to invest in your team and your junior trainees. By creating a team that can function independently without compromising patient safety, you will be able to afford to leave the hospital.

If you believe now that it is not important to be there to feed your newborn child or to read a book to your children at bedtime, you will regret this. If you miss a case, you can do the next one. If you miss a conference, you can attend the next one. If you miss an opportunity to be there for your family or friends, you will never get another chance. Your family will either leave you or accept that you are absent. Your children will no longer expect to see you at their soccer games. Your friends will stop inviting you to dinner because you either replied "no" or did not show up the previous 5 times. You need to invest in your family and friends so that you can lean on them when things get rough.

I believe wholeheartedly that cardiac surgery is the greatest and most rewarding specialty. If I had to do it all over again, I would not change a thing. I just finished my training 
in July and became a junior attending surgeon. I do not claim to be wise, and I am too inexperienced to give advice to anyone. This editorial was my attempt to share some of the lessons I learned during my 10-year training to become a pediatric heart surgeon. At the end of the day, everyone is different, and you will figure out what helps you most.

\section{References}

1. Agassi A. Open: an autobiography. New York: Alfred A Knopf; 2009.
2. Feins RH, Burkhart HM, Conte JV, Coore DN, Fann JI, Hicks GL Jr, et al. Simulation-based training in cardiac surgery. Ann Thorac Surg. 2017;103:312-21.

3. Mokadam NA, Fann JI, Hicks GL, Nesbitt JC, Burkhart HM, Conte JV, et al. Experience with the cardiac surgery simulation curriculum: results of the resident and faculty survey. Ann Thorac Surg. 2017;103:322-8.

4. Helder MR, Rowse PG, Ruparel RK, Li Z, Farley DR, Joyce LD, et al. Basic cardiac surgery skills on sale for $\$ 22.50$ : an aortic anastomosis simulation curriculum. Ann Thorac Surg. 2016;101:316-22; discussion 322.

5. Pulcano M, Evans RT, Sosin M. Quality of life and burnout rates across surgical specialties: a systematic review. JAMA Surg. 2016;151:970-8.

6. Dimou FM, Eckelberg D, Riall TS. Surgeon burnout: a systematic review. J Am Coll Surg. 2016;222:1230-9. 